\title{
Depression remains a neglected public health problem among pregnant women in Northwest Ethiopia
}

\author{
Getnet Mihretie Beyene ${ }^{1,2^{*}}$ (D) Telake Azale ${ }^{3}$, Kassahun Alemu Gelaye ${ }^{2}$ and Tadesse Awoke Ayele ${ }^{2}$
}

\begin{abstract}
Background: Antenatal depression is highly prevalent but a neglected public health problem in low income countries. It has serious effects on the general health of women, birth outcomes and child health. However, there has been limited substantial evidence on the prevalence and predictors of antenatal depression in Ethiopia. This lack of evidence potentiates the consequences of the problem and can limit the attention to intervention. Thus, this study aimed to assess the prevalence and potential predictors of antenatal depression at Debre Tabor and Woreta towns, Northeast Ethiopia.
\end{abstract}

Methods: A community-based cross-sectional study was employed on 548 pregnant women recruited by a cluster sampling method. Depressive symptoms were measured using the Edinburgh Postnatal Depression Scale (EPDS). The List of Threatening Experiences Questionnaire (LTE-Q), the Oslo-3 Social Support Scale (OSSS-3), Intimate Partner Violence (IPV) Scale and Fast Alcohol Screening Test (FAST) were also used to measure stressful events, social support, intimate partner violence (IPV) and hazardous alcohol use respectively. Bivariable and multivariable logistic regression analyses were carried out to identify factors associated with antenatal depression.

Results: The prevalence of antenatal depression was found to be $24.45 \%$ (95\% Cl: 21.20, 28.30\%). Being single (AOR $=3.32,95 \% \mathrm{Cl}=1.36,8.09)$; fear of pregnancy complication ( $\mathrm{AOR}=3.84,95 \% \mathrm{Cl}=1.53,9.62)$; history of chronic illness $(\mathrm{AOR}=8.14,95 \% \mathrm{Cl}=2.14,30.91)$; unplanned pregnancy $(\mathrm{AOR}=2.99,95 \% \mathrm{Cl}=1.36,6.55)$; history of stillbirth ( $\mathrm{AOR}=$ $3.56,95 \% \mathrm{Cl}=1.23,10.29)$, one or more negative life events ( $\mathrm{AOR}=4.06,95 \% \mathrm{Cl}=1.71,9.66)$ and intimate partner violence $(A O R=3.91,95 \% \mathrm{Cl}=1.65,9.26)$ were factors significantly associated with antenatal depression.

Conclusion: Nearly a quarter of pregnant women suffer from depressive symptoms during pregnancy. Being single; fear of pregnancy complication; history of chronic illness; unplanned pregnancy; history of stillbirth; one or more negative life events and intimate partner violence were important predictors of antenatal depression in this study. Health care workers should consider addressing these risk factors during a routine antenatal care. Also, integrating early screening, detection, and treatment of antenatal depression into routine antenatal care is warranted to improve the quality of life of pregnant women and pregnancy outcomes as well.

Keywords: Depression, Depressive symptoms, Neglected disease, pregnant, pregnant woman

\footnotetext{
* Correspondence: getnet.mihretie@gmail.com

'Department of psychiatry, College of Health Sciences, Debre Tabor University, Debre Tabor, Ethiopia

${ }^{2}$ Department of Epidemiology and Biostatistics, College of Medicine and Health Sciences, University of Gondar, Gondar, Ethiopia

Full list of author information is available at the end of the article
}

(c) The Author(s). 2021 Open Access This article is licensed under a Creative Commons Attribution 4.0 International License, which permits use, sharing, adaptation, distribution and reproduction in any medium or format, as long as you give appropriate credit to the original author(s) and the source, provide a link to the Creative Commons licence, and indicate if changes were made. The images or other third party material in this article are included in the article's Creative Commons licence, unless indicated otherwise in a credit line to the material. If material is not included in the article's Creative Commons licence and your intended use is not permitted by statutory regulation or exceeds the permitted use, you will need to obtain permission directly from the copyright holder. To view a copy of this licence, visit http://creativecommons.org/licenses/by/4.0/ The Creative Commons Public Domain Dedication waiver (http://creativecommons.org/publicdomain/zero/1.0/) applies to the data made available in this article, unless otherwise stated in a credit line to the data. 


\section{Background}

Depression is the leading cause of disease burden for women in both high-income and low- and middleincome countries [1-3]. Maternal depression is a neglected public health problem in low- and middleincome countries [4]. Depression is among the most prevalent mental health problems that occur during pregnancy, affecting about one in four women [5].

Evidence from $8 \%$ of low- and lower-middle-income countries revealed that the weighted mean prevalence of antenatal common mental disorders was estimated to be 15.6\% (95\% CI: 15.4-15.9) [6]. The occurrence of depressive symptoms increases considerably in pregnant women than non-pregnant women specifically in mid and late pregnancy $[7,8]$. During late pregnancy, fear of childbirth and dysfunctional coping styles are associated with emotional disturbance during late pregnancy [9]. World health organization reported that the prevalence rates of depressive symptoms during pregnancy in low and middle-income countries are estimated to be from $12.5-42 \%$ [10].

The prevalence rate of depression during pregnancy in low and middle-income countries is higher than in highincome countries. For example, a comparative study between Pakistani and Canadian women showed that antenatal depression was more prevalent among Pakistani women (48.4\%) than Canadian women $(31.2 \%$ for the Aboriginal and $8.6 \%$ for the Caucasians [11]. Reports in several studies carried out in different parts of the world revealed that the prevalence of antenatal depression has huge variation ranging from $3.3 \%$ in Sweden to $80 \%$ in Pakistan [12, 13].

Various rates of depressive symptoms during pregnancy have been reported from developed and developing countries such as $44.2 \%$ in the United States of America [14], 62\% in Pakistan [12], 14.2\% in Brazil [15] and $39 \%$ in South Africa [16].

In Ethiopia, the prevalence estimates of antenatal depression ranges from 6.8 to $32.3 \%$ [17-22], by using Edinburgh Postnatal Depression Scale (EPDS) with the cutoff point of $\geq 13$.

Many socio-demographic, clinical, behavioral and psychosocial factors have been reported to be associated with the occurrence and persistence of antenatal depression [19, 20, 23-25]. More frequently reported predictors of depression during pregnancy include low income $[11,16,26,27]$, unplanned pregnancy $[6,15,19,20,23$, 27-31], previous history of depression $[15,19,20,23$, $24,31]$, history of stillbirth [20, 23, 32], pregnancy complications $[6,27,31,33]$, intimate partner violence [6, $11,16,22,24,28,34,35]$, younger age [16, 20, 29], poor social support $[16,20,22,26,30,31,33,35]$, and stressful events [20, 26, 36]. Pregnancy increases the risk of depression, especially when it is unplanned, has short birth interval, there is financial difficulty and it is out of marriage [4].

In addition to the psychological suffering, untreated maternal depression is associated with adverse health and social consequences for both the mother and the child. Pregnant women with symptoms of depression experience emotional withdrawal and decreased capability to function [37, 38].

Pregnant women with symptoms of depression are more likely to use tobacco, alcohol, and drugs [39]. Moreover, they are subjected to inadequate prenatal care and poorer weight gain in pregnancy, all of which have devastating consequences to the fetus, the baby, and the mother herself [39-41].

Findings showed that untreated prenatal depression is associated with a variety of adverse perinatal outcomes including pre-term birth and low birth weight $[42,43]$, delayed breastfeeding initiation [44], intrauterine growth restriction [42], admission to neonatal intensive care unit [45] and postpartum depression [12, 41, 46, 47].

Despite the burgeoning evidence on the adverse effects of antenatal depression, the very few published studies in Ethiopia have contradicting findings. Some studies show significant association between antenatal depression and low birth weight [21], prolonged labor, and delayed initiation of breastfeeding [22], pregnancy complications, labor complication and the postpartum complications [23], risk of infant diarrhea [24], increase in non-scheduled antenatal care (ANC) visits and increased number of emergency health care visits [48], child death [25], increased assisted delivery [49], and preterm birth $[50,51]$.

Although a number of studies have been conducted in Ethiopia, most of them were in other regions with differences in socio-demography, using different tools, and change in time (affects the level of awareness on maternal depression prevention mechanisms) insists us to conduct this study in this area. Therefore, this study aimed to estimate the prevalence and potential predictors of antenatal depressive symptoms among women living at Debre Tabor and Woreta towns of Northwest Ethiopia.

\section{Methods}

\section{Study design and settings}

A community-based cross-sectional study was conducted as part of a prospective cohort study from June to August 2019 in the Northwest, Ethiopia. The study was conducted at Debre Tabor and Woreta towns which are situated in South Gondar zone. According to the South Gondar zone catchment profile, Debre Tabor town has an estimated population of 84,382 of which 40 , 753 are females and Woreta town has an estimated population of 41,668 of which 20,507 are females. 
According to the pregnancy rate, about 2844 and 1404 women were estimated to be pregnant per year at Debre Tabor and Woreta towns respectively [52]. In these towns, there were 1 hospital, 5 health centers, and 10 private health institutions providing health services during the data collection period.

At the community level, antenatal care services are carried out by health extension workers who are assigned in each Kebele; the lowest administrative unit or village in Ethiopia. According to the district health office report of the previous year, the proportion of pregnant women who were using antenatal care services at Debre Tabor and Woreta towns were estimated to be 75 and $64 \%$ respectively [52].

\section{Study population, sample size and sampling strategies} The source population consisted of all pregnant women at Debre Tabor and Woreta towns, whereas the study population was all pregnant women in the selected kebeles during the study period. All self- reporting pregnant women in the selected kebeles were eligible for the study, whereas women who were critically ill at the time of data collection were excluded from the study.

The sample size was calculated using a single population proportion formula with a proportion of $11.8 \%$ [23], precision of 4, and 95\% level of confidence (Standard Normal value of 1.96) the standard normal deviate of 1.96 at $95 \%$ confidence intervals. Considering 10\% nonresponse and design effect of 2 , the final sample size was 550.

A cluster sampling technique was employed for the selection of the study units. There are ten kebeles in both towns (Debre Tabor Town $=6$ and Woreta Town $=4$ ), from which 5 kebeles were selected randomly, by using a lottery method to represent the total population. Participants were identified by obtaining official lists of the pregnant women from health extension workers working in the areas, who routinely collect data on new pregnancies.

\section{Study variables}

The outcome variable in this study was antenatal depression. Depressive symptoms are defined as present when a pregnant woman had an EPDS score of $\geq 12$.

The independent variables were socioeconomic and demographic characteristics (maternal age, educational status, marital status, occupation, family monthly income), obstetric factors (gravidity, parity,number of live children, fear of pregnancy complication, history of abortion, modes of previous abortion, unplanned pregnancy, gestational age, history of stillbirth, previous pregnancy complication, current pregnancy complication, type of current pregnancy complication, and umber of antenatal service), Clinical Factors (previous history of depression and family history of depression, chronic illness and types of chronic illness), Psychosocial factors (social support, intimate partner violence, and stressful life events),and behavioral factors (hazardous alcohol use).

\section{Measurements}

Edinburgh Postnatal Depression Scale (EPDS): We used EPDS to measure depressive symptoms. The EPDS was validated in Ethiopia among postnatal women with a sensitivity and specificity of 78.9 and $75.3 \%$ respectively [53], and also has been validated in multiple countries for its use during pregnancy [54-57]. It includes 10 items with a Likert scale of responses scored from 0 to 3 , with a maximum score of 30 .

Edinburgh Postnatal Depression Scale is more preferable scale than other depression scales to screen depression during pregnancy, because it removes the physical symptoms of depression associated with pregnancy [58].

\section{Social support}

The Oslo3-item Social Support Scale (OSSS) [59] was used to measure social support. The level of social support is classified as "poor support" 3-8, "moderate support" 9-11 and "strong support", 12-14 scores. The OSSS- 3 contains three items assessing the number of close intimate, perceived level of concern from others and perceived ease of getting helps from neighbors. The OSSS-3 has good convergent and predictive validity [60].

\section{List of threatening experiences (LTE)}

Experiences of stressful life events during the six months before assessment were assessed using the List of Threatening Experiences (LTE) The scale contains twelve items and includes questions of death, illness, conflicts and loss of property [61]. The presence of stressful life events explained by experienced one or more stressful life events in the last 6 months. LTE has good test-retest reliability (Kappa: $0.61-0.87$ ) and predictive validity [62]. Both the list of threatening experiences (LTE-12) and the Oslo Social Support Scale (OSSS-3) have been used in a population-level study in Ethiopia [63].

\section{Intimate partner violence (IPV)}

Pregnant women were asked for their exposure to IPV using three questions, one on emotional IPV, one on physical IPV and one on sexual IPV. The presence of IPV was ascertained by the presence of at least one type of IPV [64].

Fast Alcohol Screening Test (FAST): is a 4-item selfreport measure with $0-4$ scores for item 1, 2, 3 whereas 0,2 and 4 for item 4 and a FAST positive if the total score for all four questions is $\geq 3$ [65]. 
Data collection technique and quality control issues

Data were collected by 10 trained data collectors who have experience of data collection and supervised by health officers. Data collectors and supervisors were trained for two days about the study procedures, questionnaires, data collection techniques, quality assurance procedures, and study ethics. Pretest was done at a nearby district on 58 pregnant women to check the clarity of the instrument for independent variables. Based on the finding from the pretest, the questionnaire was revised. The English version of the questionnaire was translated into Amharic and then back into English to maintain its consistency. The collected data were checked daily for completeness and consistency.

\section{Data analysis}

Data were entered, coded, and cleaned using EpiData and exported to STATA software version14 for analysis. Descriptive statistics (frequencies, percentage, means, and standard deviations) were performed.

Bivariate analysis was conducted to assess the relationship between each independent variable and the outcome variable (antenatal depression). To control for the effect of confounding factors, multivariable logistic regression was carried out including variables with a $p$ value of less than 0.2 in the bivariate analysis. The degree of association between dependent and independent variables was assessed using odds ratio with a 95\% confidence interval. Hosmer-Lemeshow's was used to test the goodness-of-fit of the model. To measure the amount of multicollinearity of associated independent variable we use inflation factor (VIF). VIF and tolerance value were less than 5 and greater than 0.1 respectively, which indicate the independent variables are not linear combinations of each other.

\section{Ethical issues}

Ethical clearance was obtained from the University of Gondar Ethical Review Board and Regional research office. Permission to conduct the study was received from Debre Tabor and Woreta towns' health department and administration offices.

Written informed consent was obtained from each participant following the provision of an outline of the purpose of the study. Confidentiality was maintained by using a nameless questionnaire and privacy was assured by interviewing the participants alone. Participants who have suicidal ideation were advised to contact psychiatric professionals.

\section{Results}

Socio-demographic characters of pregnant women

Out of 565 women recruited to participate in the study, 548 agreed (97\%), to be part of the study. The mean age of the participants was 27.5 years with $(\mathrm{SD}, \pm 5.3)$, ranging from 17 to 40 years. The majority of women 499 (91\%) were Orthodox Christians by religion. More than a quarter of the participants 148 (27\%) attended primary school. Half of the respondents 284 (51.82\%) were housewives. From all, 53 (9.7\%) women had experienced hunger in the month preceding the interview and $57(10 \%)$ had debt to buy food (Table 1).

Table 1 Socio-demographic factors among pregnant women at South Gondar Zone Towns, Northwest Ethiopia, 2020

\begin{tabular}{|c|c|c|}
\hline Characteristics & Frequency $(n=548)$ & Percent (\%) \\
\hline \multicolumn{3}{|l|}{ Age group } \\
\hline$\leq 19$ & 30 & 5.47 \\
\hline $20-24$ & 123 & 22.45 \\
\hline $25-29$ & 234 & 42.70 \\
\hline $30-34$ & 91 & 16.61 \\
\hline$>35$ & 70 & 12.77 \\
\hline \multicolumn{3}{|l|}{ Religion } \\
\hline Orthodox & 499 & 91.06 \\
\hline Muslim & 36 & 6.57 \\
\hline Protestant & 13 & 2.37 \\
\hline \multicolumn{3}{|l|}{ Ethnicity } \\
\hline Amhara & 534 & 97.45 \\
\hline Tigre & 14 & 2.55 \\
\hline \multicolumn{3}{|l|}{ Education } \\
\hline No education & 86 & 15.69 \\
\hline Primary & 148 & 27.01 \\
\hline Secondary and above & 314 & 57.30 \\
\hline \multicolumn{3}{|l|}{ Occupation } \\
\hline Housewife & 284 & 51.82 \\
\hline Employee & 126 & 22.99 \\
\hline Merchant & 106 & 19.34 \\
\hline${ }^{*}$ Others & 32 & 5.84 \\
\hline \multicolumn{3}{|l|}{ Marital status } \\
\hline Single & 97 & 17.70 \\
\hline Married & 451 & 82.30 \\
\hline \multicolumn{3}{|l|}{ Lack of food or Hunger } \\
\hline No & 495 & 90.33 \\
\hline Yes & 53 & 9.67 \\
\hline \multicolumn{3}{|l|}{ Debit } \\
\hline No & 491 & 89.60 \\
\hline Yes & 57 & 10.40 \\
\hline \multicolumn{3}{|l|}{ Income of family } \\
\hline Above the poverty line & 441 & 80.47 \\
\hline Below poverty line & 107 & 19.53 \\
\hline
\end{tabular}

*Others = daily laborer, students 


\section{Obstetric and clinical characteristics}

Among the participants who had a history of abortion, $45(80.36 \%)$ and 11 (19.64\%) reported spontaneous and induced abortions respectively. History of stillbirth was reported by $37(11.21 \%)$ of participants. The current pregnancy was unplanned for 195 (35.58\%) of participating women. One in five, $111(20.26 \%)$ and 47 (8.58\%) had a previous history of depression and family history of depression respectively (Table 2).

\section{Psychosocial characteristics}

Among the participants, 105 (19.16\%) reported experiencing one or more stressful life events during the previous six months. Regarding social support, 164 (29.93\%) of participants reported poor social support. One hundred five $(19.16 \%)$ of the participants were misusing alcohol during pregnancy (Table 3).

\section{Intimate partner violence}

Among those respondents who experienced intimate partner violence, $38.87 \%$ were exposed to sexual abuse (Fig. 1).

\section{Predictors of antenatal depression}

During bivariable analysis, we examined an association between antenatal depression and socio-demographic, obstetric, clinical, psychosocial and behavioral factors and we identified variables at $p$ value $(\mathrm{P}<0.2)$ to fit into the final model.

Being single $(\mathrm{OR}=3.32,95 \% \mathrm{CI}=1.36,8.09)$; fear of pregnancy complication $(\mathrm{OR}=3.84,95 \% \mathrm{CI}=1.53,9.62)$; history of chronic illness $(\mathrm{OR}=8.14,95 \% \mathrm{CI}=2.14$, $30.91)$; unplanned pregnancy $(\mathrm{OR}=2.99,95 \% \mathrm{CI}=1.36$, 6.55); history of stillbirth ( $\mathrm{OR}=3.56,95 \% \mathrm{CI}=1.23$, $10.29)$, one or more negative life event $(\mathrm{OR}=4.06,95 \%$ $\mathrm{CI}=1.71,9.66)$ and $\mathrm{IPV}(\mathrm{OR}=3.91,95 \% \mathrm{CI}=1.65,9.26)$ had significant association with antenatal depression in the multivariable model (Table 4).

\section{Discussion}

The prevalence of antenatal depression in this sample was $24.45 \%(95 \%$ CI: $21.20,28.30 \%)$. The following factors were associated with increased odds of antenatal depression: Being single, fear of pregnancy complication, history of chronic illness, unplanned pregnancy, history of stillbirth, negative life event and intimate partner violence (IPV).

In the current study, the prevalence of antenatal depression was in line with studies done in the United States of America 25\% [66], Canada 27\% [67], China 28.5\% [68], Brazil 21.2\% [25], Nigeria 24.5\% [29] and other studies done in Ethiopia such as Addis Ababa 24.94\% [19], Hawasa 21.5\% [20], Gondar 23\% [21], Shashemane 25.6\% [22], and Dupti Hospital 17.9\% [30].
Table 2 Frequency distribution of obstetric and clinical factors among pregnant women at South Gondar Zone Towns, Northwest Ethiopia, 2020

\begin{tabular}{lll}
\hline Characteristics & Frequency $(\boldsymbol{n}=\mathbf{5 4 8})$ & P \\
\hline Depression & \\
No & 414 \\
Yes & 134
\end{tabular}

\section{Number of live children}

$\begin{array}{lll}\text { Zero } & 20 & 6.06\end{array}$

One $\quad 148 \quad 44.85$

$\begin{array}{lll}\text { Two-four } & 154 & 46.67\end{array}$

Five and above $\quad 8 \quad 2.42$

previous pregnancy complication $(n=330)$

$\begin{array}{lll}\text { No } & 255 & 77.27\end{array}$

$\begin{array}{lll}\text { Yes } & 75 & 22.73\end{array}$

History of current pregnancy complication

No $\quad 488 \quad 88.14$

Yes $\quad 65 \quad 11.86$

Type of current pregnancy complication $(n=65)$

Anemia $23 \quad 35.38$

$\begin{array}{lll}\mathrm{APH} & 13 & 20\end{array}$

$\begin{array}{lll}\text { Edema } & 11 & 16.92\end{array}$

$\begin{array}{lll}\text { UTI } & 18 & 27.69\end{array}$

History of abortion $(n=330)$

No $\quad 274 \quad 83.03$

Yes $\quad 56 \quad 16.97$

Modes of previous abortion $(n=56)$

Spontaneous $\quad 45 \quad 80.36$

$\begin{array}{lll}\text { Assisted } & 11 & 19.64\end{array}$

Gravidity

$\begin{array}{lll}\text { One } & 218 & 39.78\end{array}$

$\begin{array}{lll}\text { Two-four } & 299 & 54.56\end{array}$

Five and above $\quad 31 \quad 5.66$

Antenatal service

$\begin{array}{lll}\text { No } & 57 & 10.40\end{array}$

$\begin{array}{lll}\text { Yes } & 491 & 89.60\end{array}$

Number of Antenatal services

$\begin{array}{lll}\text { One } & 112 & 22.81\end{array}$

$\begin{array}{lll}\text { Two } & 119 & 24.24\end{array}$

$\begin{array}{lll}\text { Three } & 148 & 30.14\end{array}$

$\begin{array}{lll}\text { Four } & 112 & 22.81\end{array}$

Previous history of depression

$\begin{array}{lll}\text { No } & 437 & 79.74\end{array}$

$\begin{array}{lll}\text { Yes } & 111 & 20.26\end{array}$

Family history of depression

$\begin{array}{lll}\text { No } & 501 & 91.42\end{array}$ 
Table 2 Frequency distribution of obstetric and clinical factors among pregnant women at South Gondar Zone Towns, Northwest Ethiopia, 2020 (Continued)

\begin{tabular}{|c|c|c|}
\hline Characteristics & Frequency $(n=548)$ & Percent (\%) \\
\hline Yes & 47 & 8.58 \\
\hline \multicolumn{3}{|l|}{$\operatorname{Parity}(n=323)$} \\
\hline One & 151 & 46.75 \\
\hline Two-four & 164 & 50.77 \\
\hline Five and above & 8 & 2.48 \\
\hline \multicolumn{3}{|c|}{ History of stillbirth $(n=330)$} \\
\hline No & 293 & 88.79 \\
\hline Yes & 37 & 11.21 \\
\hline \multicolumn{3}{|c|}{ Unplanned Pregnancy } \\
\hline Yes & 195 & 35.58 \\
\hline No & 353 & 64.42 \\
\hline \multicolumn{3}{|c|}{ Fear of pregnancy complication } \\
\hline No & 282 & 51.46 \\
\hline Yes & 266 & 48.54 \\
\hline \multicolumn{3}{|l|}{ Chronic illness } \\
\hline No & 503 & 91.79 \\
\hline Yes & 45 & 8.21 \\
\hline \multicolumn{3}{|c|}{ Type of chronic illness $(n=45)$} \\
\hline Anemia & 12 & 26.67 \\
\hline $\mathrm{CHF}$ & 10 & 22.22 \\
\hline Hypertension & 12 & 26.67 \\
\hline UTI & 11 & 24.44 \\
\hline
\end{tabular}

The result of the present study was higher than the prevalence reported in several other countries such as USA 9\% [69], South India 16\% [70], Australia 16.9\% [26], Brazil 14.2\% [15], Bangladesh 18\% [24], Portugal $18.5 \%$ [71], and at different parts of Ethiopia such as:

Table 3 Psychosocial, depression and behavioral characteristics of pregnant women at South Gondar Zone Towns, Northwest Ethiopia, 2020

\begin{tabular}{lll}
\hline Characteristics & Frequency $(\boldsymbol{n}=\mathbf{5 4 8})$ & Percent $(\%)$ \\
\hline Life treating events & & \\
No & 443 & 80.84 \\
$\quad$ Yes & 105 & 19.16 \\
Social support & & \\
$\quad$ Strong & 147 & 26.82 \\
Moderate & 237 & 43.25 \\
Poor & 164 & 29.93 \\
Alcohol misuse & & \\
No & 443 & 80.84 \\
Yes & 105 & 19.16 \\
\hline
\end{tabular}

Gondar town 6.9\% [72] and Anended woreda15.20\% [28].

The variation in prevalence might be due to methodological differences between studies \& study setting (institution vs. community-based). The antenatal depression in this study showed high prevalence because this study was conducted in a population where severely depressed pregnant women were addressed whereas in Portugal, Brazil, US, and Dubti Ethiopia the studies were conducted at health facilities where women with severe symptoms of depression could have remained at home [73]. The other difference might be due the use of different screening tools, cut-off points on screening tools and variation in sample size.

However the result of the present study was lower than the prevalence found in, the United States of America 44.2\% [14], Rawalpindi, Pakistan 62\% [12] Karachi, Pakistan 81\% [74], Korea 40.5-61.4\% [75] Cape Town peri-urban settlement, South Africa 39\% [16], rural South Africa 47\% [76] and other studies in Ethiopia Bale zone $31.5 \%$ [77], Sodo district 28.7\% [78], and Adama Hospital 31.2\% [27].

The prevalence of depression may be influenced by the time point in which symptoms of depression during pregnancy were assessed [79]. In studies such as those in South Africa and Korea recruitment of women at a later stage of pregnancy may lead to the expected burden of delivery and child-rearing might cause a higher rate of depression [80]. Besides this geographic, economic and cultural variations might also contribute to the differences.

A number of variables were found to be significantly associated with depressive symptoms during pregnancy; after adjusting the effects of other demographic, clinical, behavioral and psychosocial variables.

Unmarried women $(\mathrm{OR}=3.32,95 \% \mathrm{CI}=1.36$, 8.09) were 3.3 times more likely to experience antenatal depression as compared to those who were in marriage. The result was consistent with the findings from Nigeria $[32,81]$. This might be due to economic hardship, social isolation and parental responsibilities [82].

The results of the present study also revealed that antenatal depression is significantly associated with history of stillbirth. Pregnant women who have a history of stillbirth were 3.56 times more likely to have antenatal depression $(\mathrm{OR}=3.56,95 \% \mathrm{CI}=1.23,10.29)$ than pregnant women who have no history of stillbirth. This was supported by studies conducted in Nigeria [32], in Ethiopia like Debre Tabor [23] and Hawassa [20].

Another predictor identified in this study was unplanned pregnancy. Pregnant women who had not planned their current pregnancy $(\mathrm{OR}=2.99,95 \% \mathrm{CI}=$ $1.36,6.55)$ were 3 times more likely to have antenatal 


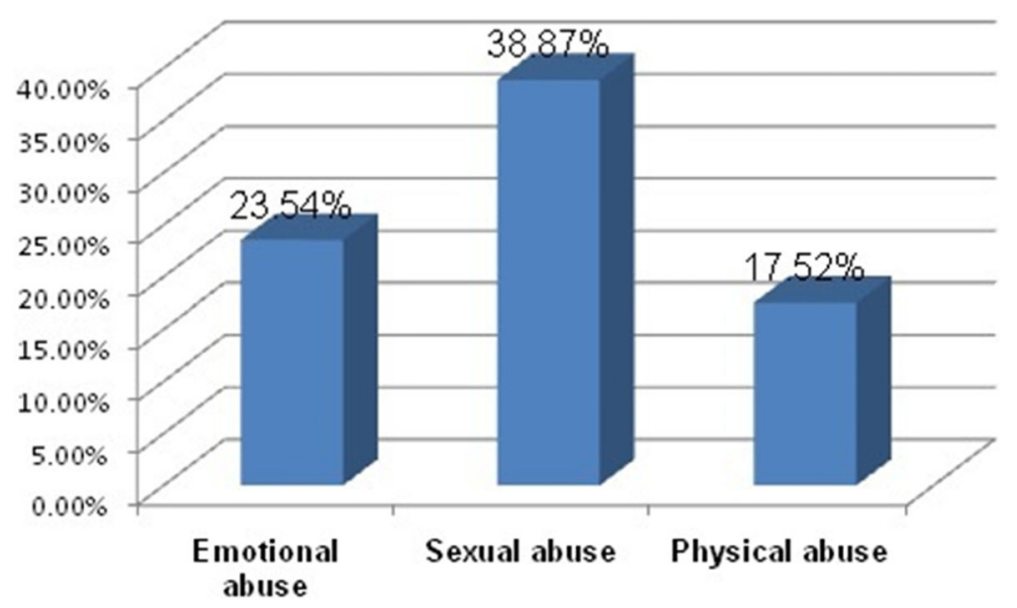

Fig. 1 The percentage of intimate partner violence among pregnant women at South Gondar Zone Towns, Northwest Ethiopia, 2020

depression than those who planned their pregnancy. This finding is in line with other studies in Ethiopia [19, 20, 23, 27, 28, 83-85], Nigeria [29], Brazil [15], Boston [86], Lithuania [87], and Pakistan [34].

Pregnant women who fear pregnancy complications $(\mathrm{OR}=3.84,95 \% \mathrm{CI}=1.53$, 9.62) were almost four times more likely to experience depression during pregnancy than those without this history. This finding is consistent with a study done in Ethiopia [27]. Women's fears associated with childbirth are pain, obstetric injury, fear of delivering a physically damaged or congenitally malformed child that might lead to psychological disturbance $[88,89]$.

Intimate partner violence (IPV) is considered important public health and human rights issue [17]. The current study revealed that intimate partner violence was strongly associated with antenatal depression. In Ethiopia, this association is a concern because domestic violence against women is highly prevalent [90], and especially in populations where low socio-economic status prevails.

The pregnant women who have experienced intimate partner violence $(\mathrm{OR}=3.91,95 \% \mathrm{CI}=1.65,9.26)$ were around four times more likely to experience depression during pregnancy than those without this history. This finding is consistent with a study done in Hyderabad, Pakistan [34], Bangladesh [24], Pakistan, Caucasian and Aboriginal [11], Ethiopia [17, 22, 28, 91], Cape Town, South Africa [16], UK [92], Bangladesh [93], and Tanzania [94].

Negative life events $(\mathrm{OR}=4.06,95 \% \mathrm{CI}=1.71$, 9.66) were significantly associated with depressive symptoms. The result was similar to the study findings in Hawassa,
Ethiopia [20, 23], Brazil [15, 25], USA [95], UK [96], and Tanzania [97].

The results indicated that serious chronic illness $(\mathrm{OR}=$ $8.14,95 \% \mathrm{CI}=2.14,30.91$ ) was by far the most powerful predictor of depressive symptoms during pregnancy, which increases the risk of depression during pregnancy by eight-fold. This is similar to findings observed in some studies in Canada [11] South Africa [76] Nigeria [29], and Brazil [98]. Depression is one of the most common complications of chronic illness. The illness may limit a person's ability to interact with others. These changes can be stressful and cause a certain amount of hopelessness or sadness [99].

Since the design is a cross-sectional study, the timing of exposures and the onset of depressive symptoms is not established for every exposure; in particular, chronic illness and depression but only to determine associations. Despite these limitations, the results of this study have significant implication. As this study confirmed that antenatal depression is high and a public health problem; health care providers and policy makers should think about routine screening of all pregnant women for depressive symptoms and to treat them at the primary health care level by integrating the service, since screening is an effective approach for plunging morbidity in depressed people [100]. The EPDS is an easy, quick screening tool to identify women with depressive symptoms, so that, it can be integrated as a part of antenatal care measurement in all health facilities. Antenatal education program and creating awareness about depressive symptoms and its associated factors, adverse effects associated with untreated depression, should be implemented at community and antenatal care levels. It will 
Table 4 Bivariable and multivariable analysis of antenatal depression among pregnant women at South Gondar Zone Towns, Northwest Ethiopia, 2020

\begin{tabular}{|c|c|c|c|c|}
\hline \multirow[t]{2}{*}{ Characteristics } & \multicolumn{2}{|c|}{ Antenatal Depression } & \multirow[t]{2}{*}{ COR at $95 \% \mathrm{Cl}$} & \multirow[t]{2}{*}{ AOR at $95 \% C$} \\
\hline & Yes & No & & \\
\hline \multicolumn{5}{|l|}{ Marital status } \\
\hline Married & 85 & 366 & 1 & 1 \\
\hline Unmarried & 49 & 48 & $4.39(2.767,6.982)$ & $3.32(1.363,8.099)^{* *}$ \\
\hline \multicolumn{5}{|c|}{ Lack of food or Hunger } \\
\hline Yes & 30 & 23 & $4.90(2.733,8.799)$ & $1.38(0.112,17.006)$ \\
\hline No & 104 & 391 & 1 & 1 \\
\hline \multicolumn{5}{|l|}{ Debit } \\
\hline Yes & 31 & 26 & $4.49(2.554,7.899)$ & $1.81(0.164,20.005)$ \\
\hline No & 103 & 388 & 1 & 1 \\
\hline \multicolumn{5}{|c|}{ Pregnancy is planned } \\
\hline Yes & 53 & 300 & 1 & 1 \\
\hline No & 81 & 114 & $4.02(2.674,6.048)$ & $2.99(1.363,6.547)^{* *}$ \\
\hline \multicolumn{5}{|c|}{ History of stillbirth $(n=330)$} \\
\hline Yes & 20 & 17 & $4.47(2.210,9.059)$ & $3.56(1.234,10.296) * *$ \\
\hline No & 61 & 232 & 1 & 1 \\
\hline \multicolumn{5}{|c|}{ Current pregnancy complication } \\
\hline Yes & 37 & 23 & $5.26(3.067,9.015)$ & $1.98(0.653,5.992)$ \\
\hline No & 97 & 391 & 1 & 1 \\
\hline \multicolumn{5}{|c|}{ Fear of pregnancy complication } \\
\hline Yes & 105 & 161 & $5.69(3.606,8.978)$ & $3.84(1.533,9.623)^{* *}$ \\
\hline No & 29 & 253 & 1 & 1 \\
\hline \multicolumn{5}{|l|}{ Chronic illness } \\
\hline Yes & 23 & 22 & $3.69(1.984,6.872)$ & $8.14(2.144,30.914) * *$ \\
\hline No & 111 & 392 & 1 & 1 \\
\hline \multicolumn{5}{|c|}{ Previous history of depression } \\
\hline Yes & 65 & 46 & $7.52(4.772,11.900)$ & $2.04(0.734,5.664)$ \\
\hline No & 69 & 368 & 1 & 1 \\
\hline \multicolumn{5}{|c|}{ Family history of depression } \\
\hline Yes & 32 & 15 & $8.35(4.353,15.997)$ & $1.65(0.343,7.942)$ \\
\hline No & 102 & 399 & 1 & 1 \\
\hline \multicolumn{5}{|c|}{ Negative life event } \\
\hline No & 67 & 376 & 1 & 1 \\
\hline Yes & 67 & 38 & $9.89(6.151,15.916)$ & $4.06(1.706,9.659) * *$ \\
\hline \multicolumn{5}{|l|}{ Social Support } \\
\hline Poor & 63 & 101 & $2.65(1.579,4.451)$ & $0.74(0.266,2.076)$ \\
\hline Moderate & 43 & 194 & $0.94(0.556,1.597)$ & $0.68(0.238,1.938)$ \\
\hline Strong & 28 & 119 & 1 & 1 \\
\hline \multicolumn{5}{|c|}{ Intimate partner violence (IPV) } \\
\hline Yes & 107 & 118 & $9.94(6.195,15.953)$ & $3.91(1.649,9.264) * *$ \\
\hline No & 27 & 296 & 1 & 1 \\
\hline \multicolumn{5}{|l|}{ Alcohol misuse } \\
\hline Yes & 41 & 64 & $2.41(1.531,3.796)$ & $1.08(0.414,2.811)$ \\
\hline
\end{tabular}


Table 4 Bivariable and multivariable analysis of antenatal depression among pregnant women at South Gondar Zone Towns, Northwest Ethiopia, 2020 (Continued)

\begin{tabular}{|c|c|c|c|c|}
\hline \multirow[t]{2}{*}{ Characteristics } & \multicolumn{2}{|c|}{ Antenatal Depression } & \multirow[t]{2}{*}{ COR at $95 \% \mathrm{Cl}$} & \multirow[t]{2}{*}{ AOR at $95 \% C$} \\
\hline & Yes & No & & \\
\hline No & 93 & 350 & 1 & 1 \\
\hline
\end{tabular}

N.B: Abbreviations: $\mathbf{C l}=$ confidence interval; $\mathbf{O R}=$ odds ratio; $\mathbf{C O R}=$ Crude odds ratio; $\mathbf{A O R}=$ Adjusted odds ratio, $1=$ Reference, Hosmer-Lemeshow goodness of fit test $=0.7630$

** $(P<0.01) ; *(P<0.05)$

alert us early screening and treatment of depression symptoms during pregnancy, may help to reduce both severity of depressive symptoms and prevent the adverse effects of depression on neonatal outcomes; moreover, it helps as a standing point for future research.

\section{Conclusion}

Nearly a quarter of pregnant women suffer from depressive symptoms during pregnancy. Being single; fear of pregnancy complication; history of chronic illness; unplanned pregnancy; history of stillbirth; one or more negative life events and intimate partner violence were important predictors of antenatal depression in this study. Health care workers consider to address these risk factors during a rutine antenatal care. Also, integrating early screening, detection, and treatment of antenatal depression into routine antenatal care is waranted to improve the quality of life of pregnant women and pregnancy outcomes as well.

\section{Abbreviations}

ANC: Ante Natal Care; AOR: Adjusted Odds Ratio; Cl: Confidence Interval; COR: Crude odds ratio; CM: Common Mental Disorder; EPDS: Edinburgh Postnatal Depression Scale; FAST: Fast Alcohol Screening Test; IPV: Intimate Partner Violence; LTE: List of Threatening Experiences; OR: Odds Ratio; OSSS3: Oslo-3 Social Support Scale

\section{Acknowledgments}

The authors would like to acknowledge the University of Gondar for providing financial support for this research project. We would like to express our thanks to the women who participated in the study for their excellent contribution to this study. Finally, our special appreciation goes to data collectors and supervisors.

\section{Provenance and peer reviewed}

Not commissioned, externally peer reviewed.

\section{Authors' contributions}

All the authors designed the study, developed the research protocol and tool, responsible for training and data collection, analyzed the data, interpreted the findings, and wrote the manuscript. Finally, all the authors read and approve the revised manuscript.

\section{Funding}

This study was conducted as part of PhD degree fulfillment funded by the University of Gondar.

\section{Availability of data and materials}

No additional data is available for this study; all the data are included in the manuscript.

\section{Declarations}

Ethics approval and consent to participate

This study was approved by the University of Gondar Ethical Review Board and Regional research office. Permission to conduct the study was received from Debre Tabor and Woreta towns' health department and administration office. Written informed consent and assent was obtained from each participant.

Consent for publication

Not applicable.

\section{Competing interests}

The authors declare that they have no competing interests.

\section{Author details}

${ }^{1}$ Department of psychiatry, College of Health Sciences, Debre Tabor University, Debre Tabor, Ethiopia. ${ }^{2}$ Department of Epidemiology and Biostatistics, College of Medicine and Health Sciences, University of Gondar, Gondar, Ethiopia. ${ }^{3}$ Department of Health Education and Behavioral Sciences, College of Medicine and Health Sciences, University of Gondar, Gondar, Ethiopia.

Received: 24 October 2020 Accepted: 21 June 2021

Published online: 12 July 2021

\section{References}

1. World Health Organization. The global burden of disease: 2004 update. 2004 http://www.who.int/entity/healthinfo/global_burden_disease.GBD_ report_2004update_full pdf. 2004.

2. Stewart DE, Gucciardi E, Grace SL. Depression. Women's Health Surveillance Report Toronto: Health Canada. 2004; :1-14.

3. Organization WH. The world health report 2002: reducing risks, promoting healthy life: World Health Organization; 2002.

4. Hanlon C. Maternal depression in low-and middle-income countries. Int Health. 2012;5(1):4-5. https://doi.org/10.1093/inthealth/ihs003.

5. Abid M, Aamir IS. Prevalence of depression among pregnant women attending antenatal clinics in Pakistan. 2017

6. Fisher J, MCd M, Patel V, Rahman A, Tran T, Ea HS. Prevalence and determinants of common perinatal mental disorders in women in low-and lower-middle-income countries: a systematic review. Bull World Health Organ. 2012;90(2):139-49. https://doi.org/10.2471/BLT.11.091850.

7. Evans J, Heron J, Francomb H, Oke S, Golding J. Cohort study of depressed mood during pregnancy and after childbirth. Bmj. 2001;323(7307):257-60. https://doi.org/10.1136/bmj.323.7307.257.

8. Fatoye FO, Adeyemi AB, Oladimeji BY. Emotional distress and its correlates among Nigerian women in late pregnancy. J Obstet Gynaecol. 2004;24(5): 504-9. https://doi.org/10.1080/01443610410001722518.

9. Demyttenaere K, Lenaerts H, Nijs P, Van Assche FA. Individual coping style and psychological attitudes during pregnancy predict depression levels during pregnancy and during postpartum. Acta Psychiatr Scand. 1995;91(2): 95-102. https://doi.org/10.1111/j.1600-0447.1995.tb09747.x.

10. World Health Organization. Maternal mental health and child health and development in low and middle income countries: report of the meeting, Geneva, Switzerland, 30 January-1 February, 2008. 2008.

11. Shah SMA, Bowen A, Afridi I, Nowshad G, Muhajarine N. Prevalence of antenatal depression: comparison between Pakistani and Canadian women. J Pak Med Assoc. 2011;61:242. 
12. Rahman A, Creed F. Outcome of prenatal depression and risk factors associated with persistence in the first postnatal year: prospective study from Rawalpindi, Pakistan. J Affect Disord. 2007;100(1-3):115-21. https://doi. org/10.1016/j.jad.2006.10.004

13. Saeed A, Raana T, Saeed AM, Humayun A. Effect of antenatal depression on maternal dietary intake and neonatal outcome: a prospective cohort. Nutr J. 2016;15(1):64. https://doi.org/10.1186/s12937-016-0184-7.

14. Brandon AR, Trivedi MH, Hynan LS, Miltenberger PD, Labat DB, Rifkin JB, et al. Prenatal depression in women hospitalized for obstetric risk. The Journal of clinical psychiatry. 2008;69(4):635-43. https://doi.org/10.4088/JCP. v69n0417.

15. Priscila K, Giovanni M, Daniel L, Lúcia A, Leticia F. Depression during pregnancy: prevalence and risk factors among women attending a public health clinic in Rio de Janeiro, Brazil. Cad Saúde Pública. 2009;25(12):272536.

16. Hartley M, Tomlinson M, Greco E, Comulada WS, Stewart J, Le Roux I, et al. Depressed mood in pregnancy: prevalence and correlates in two Cape Town peri-urban settlements. Reprod Health. 2011;8(1):9. https://doi.org/1 0.1186/1742-4755-8-9.

17. Belay S, Astatkie A, Emmelin M, Hinderaker SG. Intimate partner violence and maternal depression during pregnancy: a community-based crosssectional study in Ethiopia. PloS one. 2019;14(7):e0220003.

18. Tiki T, Taye K, Duko B. Prevalence and factors associated with depression among pregnant mothers in the west Shoa zone, Ethiopia: a communitybased cross-sectional study. Ann General Psychiatry. 2020;19:1-7.

19. Biratu A, Haile D. Prevalence of antenatal depression and associated factors among pregnant women in Addis Ababa, Ethiopia: a cross-sectional study. Reprod Health. 2015;12:99.

20. Duko B, Ayano G, Bedaso A. Depression among pregnant women and associated factors in Hawassa city, Ethiopia: an institution-based crosssectional study. Reprod Health. 2019;16(1):25. https://doi.org/10.1186/s12 978-019-0685-x.

21. Ayele TA, Azale T, Alemu K, Abdissa Z, Mulat H, Fekadu A. Prevalence and associated factors of antenatal depression among women attending antenatal care service at Gondar University Hospital, Northwest Ethiopia. PloS one. 2016;11(5):e0155125.

22. Gemta WA. Prevalence and factors associated with antenatal depression among women following antenatal care at Shashemane health facilities, South Ethiopia. Ann Glob Health. 2015;1(81):90.

23. Bisetegn TA, Mihretie G, Muche T. Prevalence and predictors of depression among pregnant women in debretabor town, northwest Ethiopia. PloS one. 2016;11(9):e0161108.

24. Nasreen HE, Kabir ZN, Forsell Y, Edhborg M. Prevalence and associated factors of depressive and anxiety symptoms during pregnancy: a population based study in rural Bangladesh. BMC Womens Health. 2011;11(1):22. https://doi.org/10.1186/1472-6874-11-22.

25. Silva $R$, Jansen $K, L S$, et al. Sociodemographic risk factors of perinatal depression: a cohort study in the public health care system. Rev Bras Psiquiatr. 2012;34(2):143-8. https://doi.org/10.1590/S1516-444620120002 00005.

26. Leigh B, Milgrom J. Risk factors for antenatal depression, postnatal depression and parenting stress. BMC psychiatry. 2008;8(1):24. https://doi. org/10.1186/1471-244X-8-24.

27. Sahile MA, Segni MT, Awoke T, Bekele D. Prevalence and predictors of antenatal depressive symptoms among women attending Adama hospital antenatal clinic, Adama, Ethiopia. Int J Nurs Midwifery. 2017;9(5):58-64.

28. Belete AH, Assega MA, Abajobir AA, Belay YA, Tariku MK. Prevalence of antenatal depression and associated factors among pregnant women in Aneded woreda, north West Ethiopia: a community based cross-sectional study. BMC Res Notes. 2019;12(1):713. https://doi.org/10.1186/s13104-019-4717-y.

29. Thompson O, Ajayi I. Prevalence of antenatal depression and associated risk factors among pregnant women attending antenatal clinics in Abeokuta north local government area, Nigeria. Depress Res Treat. 2016;2016:1-15. https://doi.org/10.1155/2016/4518979.

30. Belay YA, Moges NA, Hiksa FF, Ketema Arado K, Liben ML. Prevalence of antenatal depression and associated factors among pregnant women attending antenatal Care at Dubti Hospital: a case of pastoralist region in Northeast Ethiopia. Depress Res Treat. 2019;2019:1. https://doi.org/10.1155/2 019/3921639.
31. Getinet W, Amare T, Boru B, Shumet S, Worku W, Azale T. Prevalence and risk factors for antenatal depression in Ethiopia: systematic review. Depress Res Treat. 2018;2018:1-12. https://doi.org/10.1155/2018/3649269.

32. Adewuya AO, Ola BA, Aloba OO, Dada AO, Fasoto OO. Prevalence and correlates of depression in late pregnancy among Nigerian women. Depress Anxiety. 2007;24(1):15-21. https://doi.org/10.1002/da.20221.

33. Zegeye A, Alebel A, Gebrie A, Tesfaye B, Belay YA, Adane F, et al. Prevalence and determinants of antenatal depression among pregnant women in Ethiopia: a systematic review and meta-analysis. BMC Pregnancy Childbirth. 2018;18(1):1-11.

34. Karmaliani R, Asad N, Bann CM, Moss N, Mcclure EM, Pasha O, et al. Prevalence of anxiety, depression and associated factors among pregnant women of Hyderabad, Pakistan. Int J Soc Psychiatr. 2009;55(5):414-24. https://doi.org/10.1177/0020764008094645.

35. Lancaster CA, Gold KJ, Flynn HA, Yoo H, Marcus SM, Davis MM. Risk factors for depressive symptoms during pregnancy: a systematic review. Am J Obstet Gynecol. 2010;202(1):5-14. https://doi.org/10.1016/j.ajog.2009.09.007.

36. RAd S, Jansen K, LDdM S, IGdS M, Tomasi E, GDGd S, et al. Depression during pregnancy in the Brazilian public health care system. Rev Bras Psiquiatr. 2010;32(2):139-44.

37. Norbeck JS, Tilden VP. Life stress, social support, and emotional disequilibrium in complications of pregnancy: a prospective, multivariate study. J Health Soc Behav. 1983;24(1):30-46. https://doi.org/10.2307/21363 01.

38. Rahman A, Iqbal Z, Bunn J, Lovel H, Harrington R. Impact of maternal depression on infant nutritional status and illness: a cohort study. Arch Gen Psychiatry. 2004;61(9):946-52. https://doi.org/10.1001/archpsyc.61.9.946.

39. Zuckerman B, Amaro H, Bauchner H, Cabral H. Depressive symptoms during pregnancy: relationship to poor health behaviors. Am J Obstet Gynecol. 1989;160(5):1107-11. https://doi.org/10.1016/0002-9378(89)90170-1.

40. Bonari L, Bennett $H$, Einarson A, Koren G. Risks of untreated depression during pregnancy. Can Fam Physician. 2004;50(1):37-9.

41. Wachs TD, Black MM, Engle PL. Maternal depression: a global threat to children's health, development, and behavior and to human rights. Child Dev Perspect. 2009;3(1):51-9. https://doi.org/10.1111/j.1750-8606.2008.00077.

42. Grote NK, Bridge JA, Gavin AR, Melville JL, lyengar S, Katon WJ. A metaanalysis of depression during pregnancy and the risk of preterm birth, low birth weight, and intrauterine growth restriction. Arch Gen Psychiatry. 2010; 67(10):1012-24. https://doi.org/10.1001/archgenpsychiatry.2010.111.

43. Jarde A, Morais M, Kingston D, Giallo R, MacQueen G, Giglia L. Neonatal outcomes in women with untreated antenatal depression compared with women without depression: a systematic review and meta-analysis. JAMA Psychiatr. 2016;73(8):826-37. https://doi.org/10.1001/jamapsychiatry.2016. 0934.

44. Grigoriadis S, VonderPorten EH, Mamisashvili L, Tomlinson G, Dennis C-L, Koren $\mathrm{G}$, et al. The impact of maternal depression during pregnancy on perinatal outcomes: a systematic review and meta-analysis. J Clin Psychiatr. 2013;74(4):e321-41. https://doi.org/10.4088/JCP.12r07968.

45. CHUNG TONYKH, FRANZCOG, LAU TZEK, MRCOG, et al. Antepartum depressive symptomatology is associated with adverse obstetric and neonatal outcomes. Psychosom Med. 2001;63:830-4.

46. Wissart J, Parshad O, Kulkarni S. Prevalence of preand postpartum depression in Jamaican women. BMC Pregnancy Childbirth. 2005;5(1):15. https://doi.org/10.1186/1471-2393-5-15.

47. Da Costa D, Larouche J, Dritsa M, Brender W. Psychosocial correlates of prepartum and postpartum depressed mood. J Affect Disord. 2000;59(1):3140. https://doi.org/10.1016/S0165-0327(99)00128-7.

48. Bitew T, Hanlon C, Kebede E, Medhin G, Fekadu A. Antenatal depressive symptoms and maternal health care utilisation: a population-based study of pregnant women in Ethiopia. BMC pregnancy and childbirth. 2016;16(1):301. https://doi.org/10.1186/s12884-016-1099-1.

49. Hanlon C, Kebede E, Honikman S, Onah MN, Fekadu A. Antenatal depressive symptoms and utilisation of delivery and postnatal care: a prospective study in rural Ethiopia. BMC Pregnancy Childbirth. 2017;17:4-11.

50. Dadi AF, Miller ER, Bisetegn TA, Mwanri L. Global burden of antenatal depression and its association with adverse birth outcomes: an umbrella review. BMC Public Health. 2020;20(1):173. https://doi.org/10.1186/s12889-02 0-8293-9. 
51. Wado YD, Afework MF, Hindin MJ. Effects of maternal pregnancy intention, depressive symptoms and social support on risk of low birth weight: a prospective study from southwestern Ethiopia. PLoS One. 2014;9(5):1-7.

52. DDHO. Debetabor District Health Office annual report on maternal and child health service performance. 2018.

53. Tesfaye M, Hanlon C, Wondimagegn D, Alem A. Detecting postnatal common mental disorders in Addis Ababa, Ethiopia: Validation of the Edinburgh Postnatal Depression Scale and Kessler Scales. J Affect Disord. 2010;122(1-2):102-8. https://doi.org/10.1016/j.jad.2009.06.020.

54. Husain N, Rahman A, Husain M, Khan SM, Vyas A, Tomenson B, et al. Detecting depression in pregnancy: validation of EPDS in British Pakistani mothers. J Immigr Minor Health. 2014;16(6):1085-92. https://doi.org/10.1 007/s10903-014-9981-2.

55. Kozinszky Z, Dudas RB. Validation studies of the Edinburgh postnatal depression scale for the antenatal period. J Affect Disord. 2015;176:95-105. https://doi.org/10.1016/j.jad.2015.01.044.

56. Roof KA, James-Hawkins L, Rahim HFA, Yount KM. Validation of three mental health scales among pregnant women in Qatar. Reprod Health. 2019;16(1):149. https://doi.org/10.1186/s12978-019-0806-6.

57. Felice E, Saliba J, Grech V, Cox J. Validation of the Maltese version of the Edinburgh postnatal depression scale. Archives of women's mental health. 2006;9(2):75-80. https://doi.org/10.1007/s00737-005-0099-3.

58. Cox JL, Holden JM, Sagovsky R. Detection of postnatal depression. Development of the 10-item Edinburgh Postnatal Depression Scale. Brit J Psychiat. 1987;150:782.

59. DalgardOS DC, Lehtinen V, Vazquez-Barquero $J$, Casey $P$. Negativelifeevents, socialsupport and gender difference in depression: amultinational community survey with data from the ODINstudy. Soc Psychiatr Epidemiol. 2006;41:444-51.

60. BoenH DOS, Bjertness E. The importance of social support in the a ssociations between psychological distress and somatic health problems and socio-economic factors among older adults living at home: a crosssectional study. BMC Geriatr. 2012;12.

61. BrughaT BP, Tennant CJ. The List of Threatening Experiences: a subset of 12 life event categories with considerable long-term contextual threat. Psychol Med. 1985:15:189-94.

62. Montón-Franco C, Josefa G, Gómez-Barragán M, Sánchez-Celaya M, Ángel Díaz-Barreiros M. Psychometric properties of the List of Threatening Experiences - LTE and its association with psychosocial factors and menta disorders according to different scoring methods. Affect Disord. 2013;150: 931-40.

63. Fekadu A, Medhin G, Selamu M, Hailemariam M, Alem A. Population level mental distress in rural Ethiopia. BMC Psychiatry. 2014;14:194.

64. Rasch V, Van TN, Nguyen HTT, Manongi R, Mushi D, Meyrowitsch DW, et al. Intimate partner violence (IPV): the validity of an IPV screening instrument utilized among pregnant women in Tanzania and Vietnam. PLoS One. 2018; 13(2):e0190856. https://doi.org/10.1371/journal.pone.0190856.

65. Hodgson R, Alwyn T, John B, Thom B, Smith A. The fast alcohol screening test. Alcohol Alcohol. 2002;37(1):61-6. https://doi.org/10.1093/alcalc/37.1.61.

66. Luke S, Salihu HM, Alio AP, Mbah AK, Jeffers D, Berry EL, et al. Risk factors for major antenatal depression among low-income African American women. J Women's Health. 2009;18(11):1841-6. https://doi.org/10.1089/jwh.2008.1261.

67. Bowen A, Muhajarine N. Prevalence of antenatal depression in women enrolled in an outreach program in Canada. J Obstet Gynecol Neonatal Nurs. 2006:35(4):491-8. https://doi.org/10.1111/j.1552-6909.2006.00064.x.

68. Zeng Y, Cui Y, Li J. Prevalence and predictors of antenatal depressive symptoms among Chinese women in their third trimester: a cross-sectional survey. BMC psychiatry. 2015;15(1):66. https://doi.org/10.1186/s12888-015-04 52-7.

69. Rich-Edwards JW, Kleinman K, Abrams A, Harlow BL, McLaughlin TJ, Joffe H, et al. Sociodemographic predictors of antenatal and postpartum depressive symptoms among women in a medical group practice. J Epidemiol Community Health. 2006;60(3):221-7. https://doi.org/10.1136/jech.2005.0393 70.

70. Chandran M, Tharyan P, Muliyil J, Abraham S. Postpartum depression in cohort of women from rural area of South India: incidence and risk factors. Br J Psychiatry. 2002;181(6):499-504. https://doi.org/10.1192/bjp.181.6.499.

71. Figueiredo B, Pacheco A, Costa R. Depression during pregnancy and the postpartum period in adolescent and adult Portuguese mothers. Archives of women's mental health. 2007;10(3):103-9. https://doi.org/10.1007/s00737007-0178-8.
72. Dadi AF, Miller ER, Woodman R, Bisetegn TA, Mwanri L. Antenatal depression and its potential causal mechanisms among pregnant mothers in Gondar town: application of structural equation model. BMC Pregnancy Childbirth. 2020;20(1):1-15.

73. Alder J, Fink N, Bitzer J, Hösli I, Holzgreve W. Depression and anxiety during pregnancy: a risk factor for obstetric, fetal and neonatal outcome? A critical review of the literature. J Matern Fetal Neonatal Med. 2007;20(3):189-209. https://doi.org/10.1080/14767050701209560.

74. SAM J, Mi A, Ri A, Si S, Ea AM. Prevalence of Depression among Pregnant Women Attending Antenatal Clinics in Pakistan. Acta Psychopathol. 2017;3:54.

75. J-h P, Karmaus W, Zhang H. Prevalence of and risk factors for depressive symptoms in Korean women throughout pregnancy and in postpartum period. Asian Nurs Res. 2015;9(3):219-25.

76. Rochat TJ, Tomlinson M, Bärnighausen T, Newell M-L, Stein A. The prevalence and clinical presentation of antenatal depression in rural South Africa. J Affect Disord. 2011;135(1):362-73. https://doi.org/10.1016/j.jad.2011. 08.011 .

77. Tefera TB, Erena AN, Kuti KA, Hussen MA. Perinatal depression and associated factors among reproductive aged group women at Goba and Robe Town of Bale Zone, Oromia Region,South East Ethiopia. Matern Health Neonatol Perinatol. 2015;1:12.

78. Bitew T, Hanlon C, Kebede E, Honikman S, Onah MN, Fekadu A. Antenatal depressive symptoms and utilisation of delivery and postnatal care: a prospective study in rural Ethiopia. BMC pregnancy and childbirth. 2017; 17(1):206. https://doi.org/10.1186/s12884-017-1383-8.

79. Bennett HA, Einarson A, Taddio A, Koren G, Einarson TR. Prevalence of depression during pregnancy: systematic review. Obstet Gynecol. 2004; 103(4):698-709. https://doi.org/10.1097/01.AOG.0000116689.75396.5f.

80. Chung $\mathrm{M}-\mathrm{Y}$, Hwang $\mathrm{K}-\mathrm{H}$, Cho $\mathrm{O}-\mathrm{H}$. Relationship between fatigue, sleep disturbance, and gestational stress among pregnant women in the late stages. Korean J Women Health Nurs. 2014;20(3):195-203. https://doi.org/1 0.4069/kjwhn.2014.20.3.195

81. Marcus S, Flynn H, Barry K, Tandon R, Greden J. Depression in pregnancy and postpartum: a review of critical issues. Postgrad Obstet Gynecol. 2000; 20(13):1-8.

82. Pearlin LI, Johnson JS. Marital status, life-strains and depression. Am Sociol Rev. 1977:42(5):704-15. https://doi.org/10.2307/2094860.

83. Hanlon C, Whitley R, Wondimagegn D, Alem A, Prince M. Between life and death: exploring the sociocultural context of antenatal mental distress in rural Ethiopia. Archives of women's mental health. 2010;13(5):385-93. https://doi.org/10.1007/s00737-010-0149-3.

84. Belay YA, Moges NA, Hiksa FF, Arado KK, Liben ML. Prevalence of antenatal depression and associated factors among pregnant women attending antenatal care at Dubti hospital: a case of pastoralist region in Northeast Ethiopia. Depress Res Treat. 2018;2018:1-9. https://doi.org/10.1155/2018/1 659089.

85. Dibaba Y, Fantahun M, Hindin MJ. The association of unwanted pregnancy and social support with depressive symptoms in pregnancy: evidence from rural southwestern Ethiopia. BMC Pregnancy Childbirth. 2013;13(1):135. https://doi.org/10.1186/1471-2393-13-135.

86. Janet W, Kleinman K, Abrams A, Bernard L, Thomas J, et al. Sociodemographic predictors of antenatal and postpartum depressive symptoms among women in a medical group practice. J Epidemiol Community Health. 2006;60:221-7.

87. Bunevicius R, Kusminskas L, Bunevicius A, Nadisauskiene RJ, Jureniene K, Pop VJ. Psychosocial risk factors for depression during pregnancy. Acta Obstet Gynecol Scand. 2009;88(5):599-605. https://doi.org/10.1080/0001634 0902846049.

88. Szeverenyi P, Poka R, Hetey M, Török Z. Contents of childbirth-related fear among couples wishing the partner's presence at delivery. J Psychosom Obstet Gynecol. 1998;19(1):38-43. https://doi.org/10.3109/0167482 9809044219.

89. Hanna-Leena MR. Experiences of fears associated with pregnancy and childbirth: a study of 329 pregnant women. Birth. 2002;29(2):101-11. https:// doi.org/10.1046/j.1523-536X.2002.00170.X.

90. Deyessa N, Berhane Y, Alem A, Ellsberg M, Emmelin M, Hogberg U, et al. Intimate partner violence and depression among women in rural Ethiopia: a cross-sectional study. Clin Pract Epidemiol Ment Health. 2009;5(1):8. https:// doi.org/10.1186/1745-0179-5-8.

91. Deyessa N, Berhane Y, Alem A, Ellsberg M, Emmelin M, Kullgren G. Intimate partner violence and depression among women in rural Ethiopia: a cross- 
sectional study. Clin Pract Epidemiol Ment Health. 2009;5(1):8. https://doi. org/10.1186/1745-0179-5-8.

92. Chandan JS, Thomas T, Bradbury-Jones C, Russell R, Bandyopadhyay S, Nirantharakumar $\mathrm{K}$, et al. Female survivors of intimate partner violence and risk of depression, anxiety and serious mental illness. Br J Psychiatry. 2020; 217(4):562-7.

93. Esie P, Osypuk TL, Schuler SR, Bates LM. Intimate partner violence and depression in rural Bangladesh: accounting for violence severity in a high prevalence setting. SSM-Popul Health. 2019;7:100368. https://doi.org/10.101 6/j.ssmph.2019.100368.

94. Manongi R, Rogathi J, Sigalla G, Mushi D, Rasch V, Gammeltoft T, et al. The association between intimate partner violence and signs of depression during pregnancy in Kilimanjaro Region, Northern Tanzania. J Interpers Violence. 2020;35(23-24):5797-811.

95. Jesse DE, Walcott-McQuigg J, Mariella A, Swanson MS. Risks and protective factors associated with symptoms of depression in low-income African American and Caucasian women during pregnancy. Journal of Midwifery \& Women's Health. 2005;50(5):405-10. https://doi.org/10.1016/j.jmwh.2005.05. 001.

96. Michalak EE, Wilkinson C, Hood K, Dowrick C, Wilkinson G. Seasonality, negative life events and social support in a community sample. Br J Psychiatry. 2003;182:434-8.

97. Jenkins R, Mbatia J, Singleton N, White B. Common mental disorders and risk factors in urban Tanzania. Int J Environ Res Public Health. 2010;7(6): 2543-58. https://doi.org/10.3390/ijerph7062543.

98. Pereira PK, Lovisi GM, Pilowsky DL, Lima LA, Legay LF. Depression during pregnancy: prevalence and risk factors among women attending a public health clinic in Rio de Janeiro, Brazil. Cadernos de Saúde Pública. 2009; 25(12):2725-36. https://doi.org/10.1590/S0102-311X2009001200019.

99. Goldberg J. Coping with chronic illness and depression. 2012.

100. FORCE USPST. U.S. Preventive Services Task Force Now Finds Sufficient Evidence To Recommend Screening Adults For Depression. Available from: http://www.medicalnewsservice.com/fullstory.cfm?storylD=1031\&fback=yes. U.S. PREVENTIVE SERVICES TASK FORCE. 2002.

\section{Publisher's Note}

Springer Nature remains neutral with regard to jurisdictional claims in published maps and institutional affiliations.

Ready to submit your research? Choose BMC and benefit from:

- fast, convenient online submission

- thorough peer review by experienced researchers in your field

- rapid publication on acceptance

- support for research data, including large and complex data types

- gold Open Access which fosters wider collaboration and increased citations

- maximum visibility for your research: over $100 \mathrm{M}$ website views per year

At $\mathrm{BMC}$, research is always in progress.

Learn more biomedcentral.com/submissions 